\title{
Altitudinal population structure and microevolution of the malaria vector Anopheles cruzii (Diptera: Culicidae)
}

\author{
Camila Lorenz ${ }^{1,2^{*}}$, Tatiani Cristina Marques ${ }^{3}$, Maria Anice Mureb Sallum ${ }^{3}$ and Lincoln Suesdek ${ }^{1,4}$
}

\begin{abstract}
Background: In Brazil, the autochthonous transmission of extra-Amazonian malaria occurs mainly in areas of the southeastern coastal Atlantic Forest, where Anopheles cruzii is the primary vector. In these locations, the population density of the mosquito varies with altitude (5-263 m above sea level), prompting us to hypothesise that gene flow is also unevenly distributed. Describing the micro-geographical and temporal biological variability of this species may be a key to understanding the dispersion of malaria in the region. We explored the homogeneity of the An. cruzii population across its altitudinal range of distribution using wing shape and mtDNA gene analysis. We also assessed the stability of wing geometry over time.
\end{abstract}

Methods: Larvae were sampled from lowland (5-20 m) and hilltop (81-263 m) areas in a primary Atlantic Forest region, in the municipality of Cananéia (State of São Paulo, Brazil). The right wings of males and females were analysed by standard geometric morphometrics. Eighteen landmarks were digitised for each individual and a discriminant analysis was used to compare samples from the hilltop and lowland. A 400-bp DNA fragment of the mitochondrial cytochrome oxidase gene subunit I (CO-I) was PCR-amplified and sequenced.

Results: Wing shapes were distinct between lowland and hilltop population samples. Results of cross-validated tests based on Mahalanobis distances showed that the individuals from both micro-environments were correctly reclassified in a range of 54-96\%. The wings of hilltop individuals were larger. The CO-I gene was highly polymorphic (haplotypic diversity $=0.98$ ) and altitudinally structured $(\Phi s t=0.085$ and Jaccard $=0.033$ ). We found 60 different haplotypes but only two were shared by the lowland and hilltop populations. Wing shape changed over the brief study period (2009-2013).

Conclusions: Wing geometry and CO-I gene analysis indicated that An. cruzii is vertically structured. Wing shape varied rapidly, but altitude structure was maintained. Future investigations should identify the biotic/abiotic causes of these patterns and their implications in the local epidemiology of malaria.

Keywords: Culicidae, Wing, Geometric morphometrics, Mitochondrial gene, Atlantic Forest

\section{Background}

Anopheles (Kerteszia) cruzii is a neotropical mosquito that employs the bromeliad phytotelmata as a larval habitat. Females blood-feed on humans as well as on other mammals and birds [1]. This mosquito occurs in natural forest ecosystems [2,3] and forest fragments [4].

\footnotetext{
*Correspondence: camilalorenz@usp.br

${ }^{1}$ Instituto Butantan, Avenida Vital Brazil, 1500, São Paulo CEP 05509-300, Brazil Biologia da Relação Patógeno-Hospedeiro, Instituto de Ciências Biomédicas, University of Sao Paulo, Av. Prof. Lineu Prestes, 2415, São Paulo CEP 05508-000, Brazil

Full list of author information is available at the end of the article
}

In spite of its occurrence in forest ecosystems impacted by human activities, An. cruzii is mainly a sylvatic species with a low synanthropy index [5]. This mosquito can feed on blood during the day and at night; however, its activity peaks in twilight periods [6-9]. It is a primary vector of Plasmodium spp. parasites in areas within the Atlantic Forest biome in Brazil, especially in the States of São Paulo, Paraná, and Santa Catarina $[2,10,11]$.

Individuals of An. cruzii were found naturally infected with Plasmodium spp. oocysts in the intestine and sporozoites in the salivary glands [12-15]. In rural areas of 
the Juquitiba and São Vicente municipalities, eastern Sao Paulo state, An. cruzii was infected with Plasmodium vivax (0.149\%), Plasmodium vivax strain VK247 (0.086\%), and either Plasmodium brasilianum or Plasmodium malariae [2]. The occurrence of these species was positively associated with maintenance of transmission of human Plasmodium in the Atlantic Forest in the states of Sao Paulo and Rio de Janeiro [14] in cycles that involve humans, Alouatta, and Cebus primates [11]. The infective biting rate was low in areas in which infected An. cruzii were found; however, the abundance of the mosquito and voracious blood-feeding behaviour maintain the endemic circulation of human Plasmodium in some areas within the Atlantic Forest domain. Furthermore, An. cruzii is a vector of Plasmodium simium and Plasmodium brasilianum, which cause simian malaria $[16,17]$. The coastal region of the Atlantic Forest shelters primate species that can be infected by $P$. simium and $P$. brasilianum; these parasites can be occasionally transmitted to humans by infective Kerteszia bites $[17,18]$.

In an ecological study conducted in the municipality of Cananéia as biological markers and sampled individuals of An. cruzii from in Sao Paulo state, Marques et al. [19] found that An. cruzii is heterogeneously distributed across different altitudes in the Atlantic Forest. The authors assessed the distribution of An. cruzii in three microenvironments, which were grouped based on altitude (lowland: 5-20 m, hill slope: $33-54 \mathrm{~m}$, and hilltop: 81-263 m altitude). Follow-up was monthly for one year; results showed that this species occurred more densely in the hilltop, presumably due to ecological preferences. We then hypothesised that gene flow is not homogeneously distributed across the altitude range and sought to determine the transience of this scenario. The aim of this study was to determine 1) if individuals of Anopheles cruzii from lowland and hilltop are morphogenetically similar and 2) if the biological variability of An. cruzii is stable over time. To address these questions, we used wing geometry and CO-I mitochondrial DNA sequences as biological markers and sampled individuals of An. cruzii from Cananéia municipality from 2009-2013.

\section{Methods}

\section{Study area}

The municipality of Cananéia is situated in a wellpreserved forest in the Atlantic Forest biome (Figure 1), southeastern Sao Paulo state, Brazil. It won status as part of the natural heritage of humanity by the United Nations Organization for Education, Science and Culture (UNESCO) in 1999, because of the ecological importance of its estuarine lagoon complex [20]. According to the Research Centre for Weather and Climate applied to Agriculture [21], the region of Cananéia experiences an annual average temperature of $24^{\circ} \mathrm{C}$ and average rainfall of $2.8 \mathrm{~mm}$. The vegetation in the area is Submontane

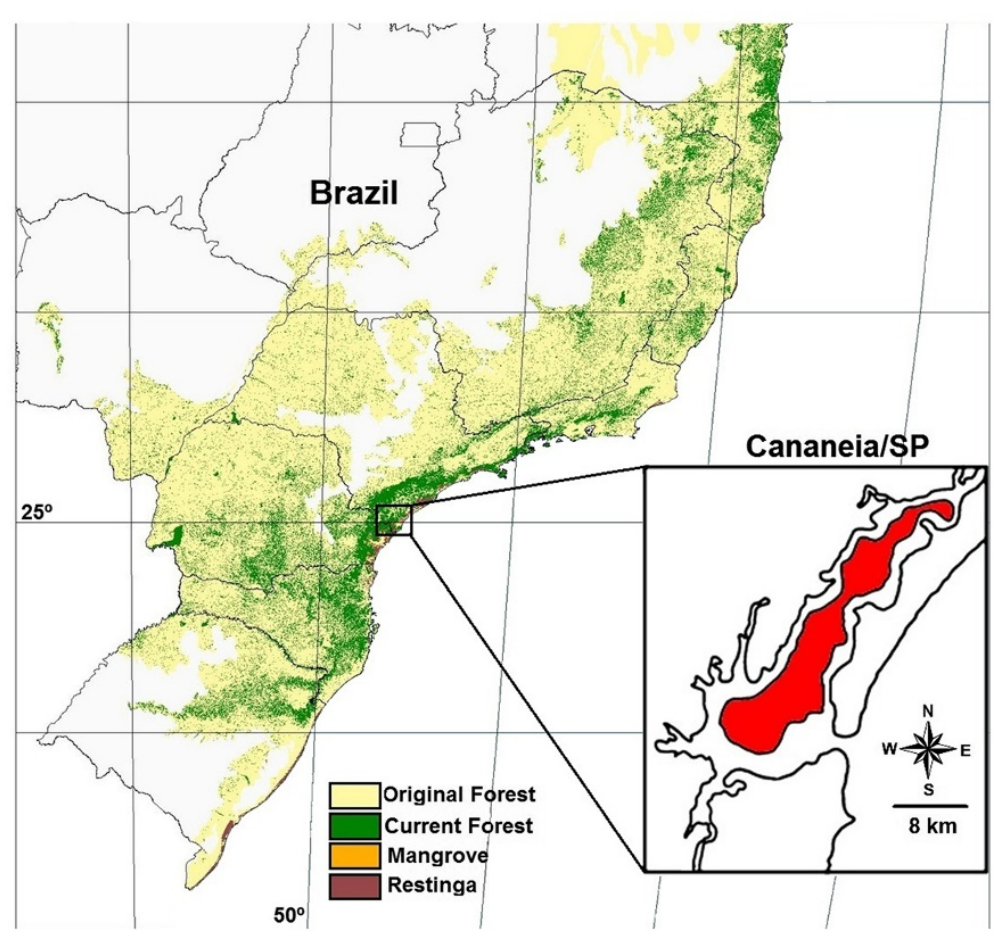

Figure 1 Study area. Cananéia municipality in red, modified from IBGE [22]. 
Table 1 Number of individuals used for geometric morphometrics and date of capture of Anopheles cruzii

\begin{tabular}{|c|c|c|c|c|}
\hline \multirow[t]{2}{*}{ Month } & \multicolumn{2}{|c|}{ Hilltop } & \multicolumn{2}{|c|}{ Lowland } \\
\hline & $0^{7}$ & $\bar{q}$ & $0^{x}$ & $\bar{q}$ \\
\hline JAN/2009 & 22 & 26 & 21 & 28 \\
\hline JAN/2012 & 22 & 24 & 24 & 26 \\
\hline JUL/2012 & 32 & 32 & 26 & 31 \\
\hline JAN/2013 & 25 & 25 & 25 & 26 \\
\hline
\end{tabular}

Forest that may extend to an altitude of $400 \mathrm{~m}$. Mosquito field collections were conducted in the Aroeira District (250'54"S and 4755'37" W, SAD 69).

\section{Mosquito collection}

Immature $A n$. cruzii individuals were taken from water accumulated inside the tanks of terrestrial and epiphytic bromeliads located up to three meters from the ground. Larvae, pupae, and eggs were collected from the water with a manual pump [23] and kept in the laboratory until emergence of the adults. Species identifications were based on characteristics of the fourth-instar larvae and pupae using the identification key proposed by Forattini et al. [3] and characteristics suggested by Sallum et al. [24].

Collection sites were separated into two microenvironments, lowland (5-20 m altitude) and hilltop (81-263 m altitude) landscape categories, both inside a well preserved forest ecosystem. The lowland areas were characterized by high humidity, high tree density, and little sunlight at ground level. In contrast, hilltop areas were abundant in rocky outcrops, tree density and humidity were low, and there was more sunlight at ground level. Co-ordinates of collection sites are described in Additional file 1. A ground distance of $470 \mathrm{~m}$ separates the closest sites between lowland and hilltop; the maximum distance was $1880 \mathrm{~m}$.

Field collections were carried out in January 2012, July 2012, and January 2013. Representatives from the January 2009 population were those reported by Marques et al. [19]. The water from each bromeliad tank was kept separate in 500-mL plastic containers in the laboratory under controlled temperature $\left(25 \pm 1^{\circ} \mathrm{C}\right)$ and humidity (80 $\pm 10 \%)$. Food and larval density in the container were similar for all collections. After emerging, the adults were euthanized and stored in $95 \%$ ethanol at $-80^{\circ} \mathrm{C}$.

\section{Morphometric analysis}

All specimens (Table 1) had their right wings removed and mounted on a microscope slide with Canada balsam. Before mounting, wings were soaked for $12 \mathrm{~h}$ in $10 \%$ potassium hydroxide $(\mathrm{KOH})$ at room temperature, according to Lorenz et al. [25]. Images of the wings were obtained with a Leica DFC320 digital camera coupled to a Leica S6 microscope under $40 \times$ magnifications. All digital images were scored by the principal author (CL).

For each wing, the co-ordinates of 18 landmarks previously employed by Lorenz et al. [25] and Vidal et al. [26] were digitized (Figure 2) and assembled into matrices using TpsDig 2.17 [27]. The co-ordinates were analysed using TpsRelw 1.34 [28] to calculate the consensus configurations and relative warps. The variability in wing shape was assessed using a Canonical Variate Analysis (CVA) to compare populations by landscape and sex. For overall wing sizes of Anopheles cruzii, we used the isometric estimator centroid size using TpsRelw 1.34 [28]. The allometric constraints between wing-shape measurements and centroid size were addressed by linear regression of the first relative warp (RW1) on centroid size. To test the accuracy of morphometric classification, each individual was reclassified according to its wing similarity to the average shape of each group (cross-validation). The graphics were generated using Statistica 7.0 [29] and edited with Adobe Photoshop 6.01 (Adobe Systems, San Jose, $\mathrm{CA})$ to overlap the $2 \mathrm{D}$ splines. Mahalanobis distances were used to estimate metric distance. The $\mathrm{Q}_{\mathrm{ST}}$ values were estimated from metric variation in wing shape and size according to Dujardin [30]. Q $\mathrm{ST}_{\mathrm{ST}}$ separates quantitative genetic variation in a process analogous to Fst for single gene markers [30,31]. Morphometric analyses, $\mathrm{Q}_{\mathrm{ST}}$, and influential landmarks tests were conducted with COV [32], TET [33], MorphoJ 1.02 [34], and TPS [35].

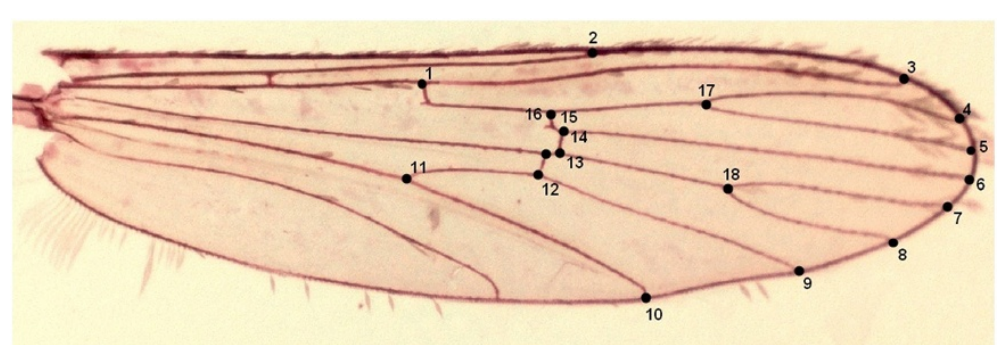

Figure 2 Wing of Anopheles cruzii. Wing dyed with acid fuchsine showing the 18 landmarks chosen for morphometric analysis. 
Table 2 Data of sexual dimorphism of An. cruzii using geometric morphometrics

\begin{tabular}{|c|c|c|c|c|c|}
\hline \multirow[t]{2}{*}{ Month } & & \multicolumn{2}{|c|}{ Cross-validation (\%) } & \multirow{2}{*}{$\begin{array}{l}\text { Allometry } \\
\text { (\%) }\end{array}$} & \multirow{2}{*}{$\begin{array}{l}\text { Influential } \\
\text { landmark }\end{array}$} \\
\hline & & $0^{\pi}$ & 우 & & \\
\hline \multirow[t]{2}{*}{ JAN/2009 } & Hilltop & 81 & 93 & $10.470^{*}$ & $\# 10$ and $\# 17$ \\
\hline & Lowland & 100 & 100 & $15.968^{*}$ & $\# 2$ and \#9 \\
\hline \multirow[t]{2}{*}{ JAN/2012 } & Hilltop & 87 & 96 & $5.853^{*}$ & $\# 2$ and \#9 \\
\hline & Lowland & 76 & 77 & 2.141 & $\# 10$ and $\# 17$ \\
\hline \multirow[t]{2}{*}{ JUL/2012 } & Hilltop & 83 & 90 & $6.909^{*}$ & $\# 2$ and \#9 \\
\hline & Lowland & 92 & 95 & $5.924^{*}$ & $\# 9$ and \#10 \\
\hline \multirow[t]{2}{*}{ JAN/2013 } & Hilltop & 96 & 100 & $8.433^{*}$ & $\# 9$ and \#10 \\
\hline & Lowland & 100 & 100 & $3.962^{*}$ & $\# 9$ and \#10 \\
\hline
\end{tabular}

$\left({ }^{*} p<0.01\right)$.

\section{Extraction, amplification, and purification of mtDNA}

Mosquitoes were homogenized as described by Jowett [36] for extraction of genomic DNA. A total of 96 specimens of $A n$. cruzii were used for genetic analysis. We used all the individuals collected in January 2012 (Table 1); the same sample was used for geometric morphometrics analyses. The CO-I gene fragment was PCR amplified in a reaction mixture of $1 \times$ buffer $(20 \mathrm{mM}$ Tris- $\mathrm{HCl}, \mathrm{pH}=8.4$ ), $0.4 \mathrm{mM}$ dNTP, $2.5 \mathrm{mM} \mathrm{MgCl} 2$, $0.5 \mathrm{mM}$ each primer, $0.5 \mu \mathrm{l} \mathrm{Taq}$ polymerase, $2.5 \mu \mathrm{l}$ genomic DNA, and sterile water to a final volume of $20 \mu \mathrm{l}$. A 407-bp fragment of the CO-I gene was amplified with forward primer UEA-7 and reverse primer UEA-10 [37], and did not include the barcode region of mitochondrial DNA. Cycling conditions were as follows: $95^{\circ} \mathrm{C}$ for $3 \mathrm{~min}$ followed by 40 cycles of $94^{\circ} \mathrm{C}$ for $40 \mathrm{~s}, 52^{\circ} \mathrm{C}$ for $40 \mathrm{~s}$, and $72^{\circ} \mathrm{C}$ for $1 \mathrm{~min}$, and a final extension of $72^{\circ} \mathrm{C}$ for $10 \mathrm{~min}$. The GenBank accession numbers for the sequences obtained are: KC992738-KC992770. The PCR products were cleaned with a PureLink ${ }^{\mathrm{TM}}$ PCR Purification kit (Invitrogen Corporation, Melle, Germany) according to manufacturer instructions. The fragment was sequenced in the forward and reverse directions with ABI PRISM dGTP BigDye ${ }^{\bullet}$ Terminator v3 (Lincoln Centre Drive, Foster City, CA).

\section{Sequencing mtDNA and data analysis}

The purified PCR products and an aliquot of the oligonucleotides specific for the CO-I gene $(40 \mathrm{pmol} / \mathrm{L})$ were sent to bio-molecular company Genomic and Molecular Engineering for sequencing on an Applied Biosystems model 3130xl sequencer. These sequences were aligned and edited with the program MEGA 5.0 [38]. The hypothesis of strict neutrality was examined with statistics D [39] and F [40] and was tested with the program DnaSP v5 [41]. Analysis of haplotype diversity and the number of polymorphic sites were calculated with MEGA 5.0 [38] using Kimura 2-parameter distance. The Фst value, which estimates the genetic differentiation by molecular variance (AMOVA), was generated by the software ARLEQUIN 3.5.2.1 [42]. Genetic analysis of population differentiation and nucleotide diversity were also calculated with Arlequin software and a haplotype network was constructed with TCS 1.12 [43]. To test the similarity between hilltop and lowland haplotypes, we used Jaccard's coefficient according to Real [44].

\section{Results}

\section{Altitudinal comparisons of chronological samples}

Canonical variate analysis revealed sexual dimorphism of wing shape in all populations. To verify that wing shape differentiation was significant between the sexes, the scores of Mahalanobis distance and reclassification between males and females were calculated after removal of the allometric effect of size. The cross-validated reclassification accuracy based on the Mahalanobis distances ranged from 76-100\% between males and females (Table 2). The greatest divergence occurred between males and females in lowland samples from January 2013, whereas the least divergence occurred in hilltop samples from July 2012. Figure 3 shows the variation of

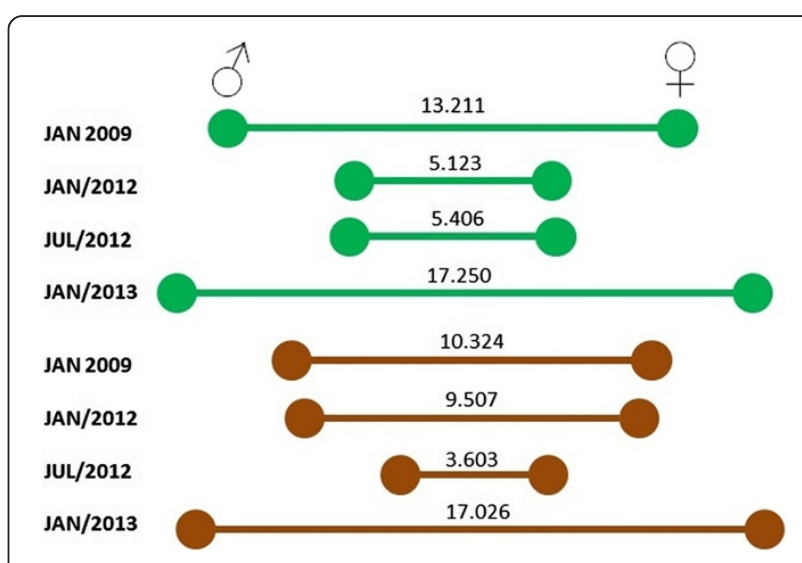

Figure 3 Sexual dimorphism over time. Mahalanobis distance between males and females in lowland (green) and hilltop (brown). 
Mahalanobis distance over time between males and females in the lowland and hilltop populations. Most comparisons showed the wing size of both sexes was similar (data not shown). The most influential landmarks to differentiate males and females in each population were always the same pairs: \#10 and \#17, \#2 and \#9, or
$\# 9$ and \#10. With the exception of the population sampled in January 2012, all other collections exhibited significant allometry (Table 2).

Anopheles cruzii showed sexual dimorphism; thus, we examined males and females separately in the next altitudinal analyses. Comparing the lowland and hilltop

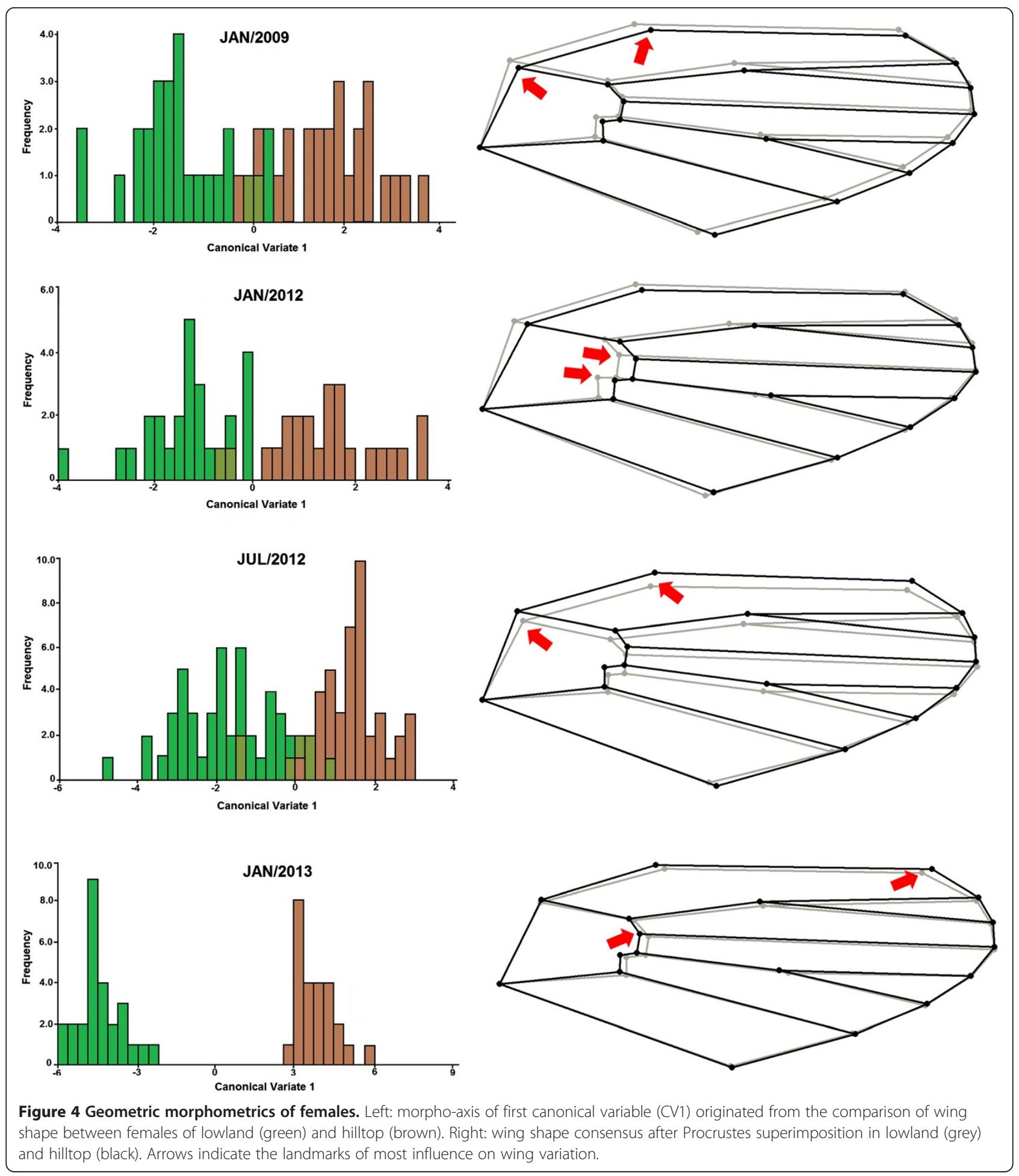


microenvironments, we noted that individuals exhibited differentiation of wing shape in all analysed populations. CVA indicated two different morpho-axis groups and we observed a separation between lowland and hilltop specimens (Figures 4 and 5). The comparison of the wing shape consensus after the Procrustes superimposition revealed a different landmark displacement for each microenvironment.

The cross-validated reclassification accuracy of each individual based on the Mahalanobis distances ranged from 54-96\% between lowland and hilltop, according to individual wing similarity to the average shape of each

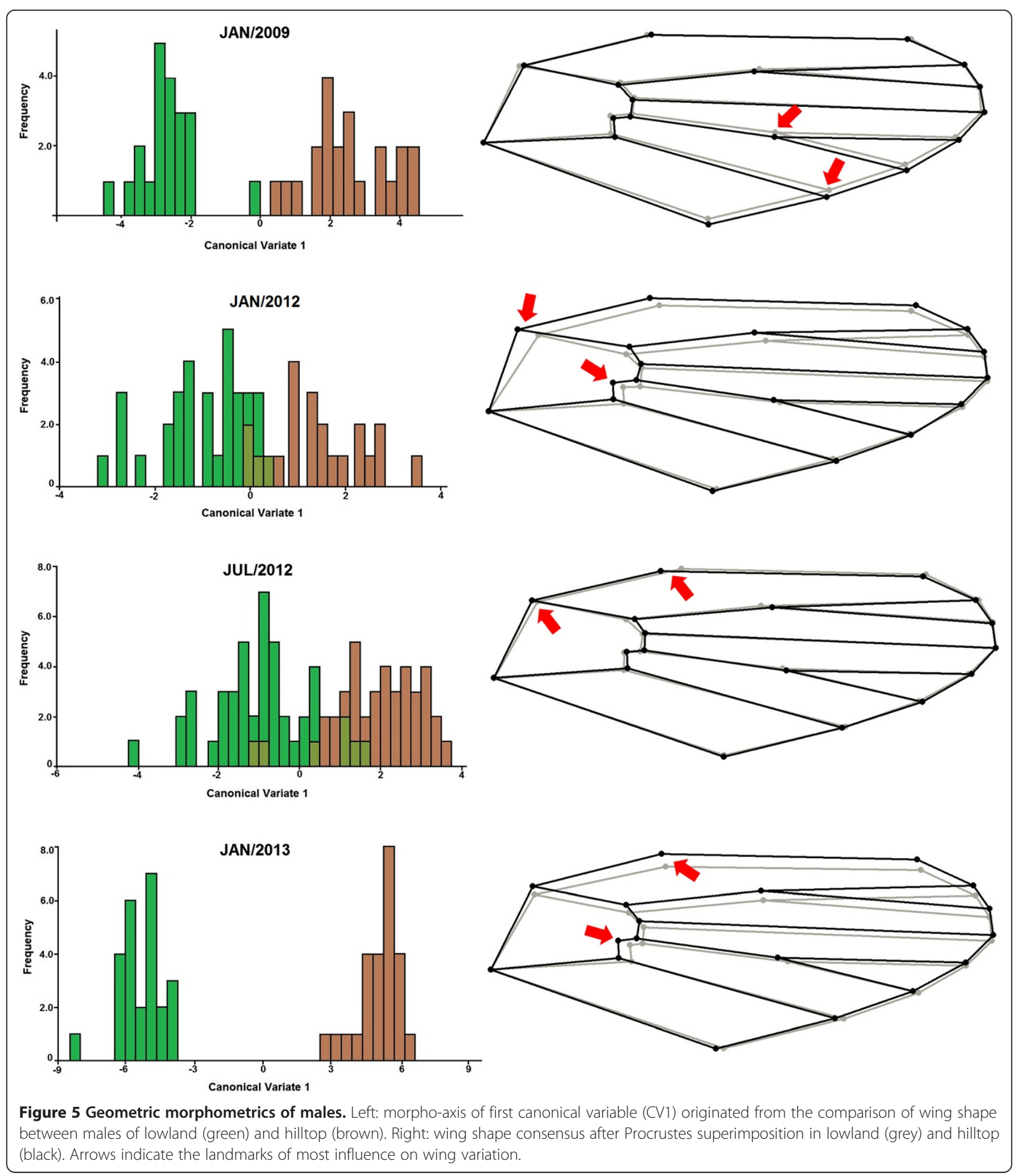


Table 3 Altitudinal comparisons between hilltop and lowland using geometric morphometrics

\begin{tabular}{|c|c|c|c|c|c|c|c|c|c|c|}
\hline & \multirow[t]{2}{*}{ Month } & \multirow{2}{*}{$\begin{array}{l}\text { Mahalanobis distance } \\
\text { Hilltop X Lowland }\end{array}$} & \multirow{2}{*}{$\begin{array}{c}\text { Allometry } \\
(\%)\end{array}$} & \multicolumn{2}{|c|}{ Cross-validation (\%) } & \multicolumn{2}{|c|}{ Centroid size $(\mathrm{mm})$} & \multirow{2}{*}{$\begin{array}{l}\text { Influential } \\
\text { Landmark }\end{array}$} & \multicolumn{2}{|l|}{$\mathrm{Q}_{\mathrm{ST}}$} \\
\hline & & & & Hilltop & Lowland & Hilltop & Lowland & & Size & Shape \\
\hline \multirow[t]{4}{*}{ q } & JAN/2009 & 2.980 & $12.736^{*}$ & 54 & 63 & 1.623 & 1.591 & $\# 1$ and \#2 & 0.40 & 0.28 \\
\hline & JAN/2012 & 2.818 & 3.799 & 54 & 53 & 1.519 & 1.455 & $\# 13$ and \#15 & 0.50 & 0.25 \\
\hline & JUL/2012 & 2.542 & $6.548^{*}$ & 75 & 73 & $1.760^{*}$ & $1.710^{*}$ & $\# 1$ and \#2 & $0.87^{*}$ & 0.27 \\
\hline & JAN/2013 & 8.112 & $5.359^{*}$ & 91 & 88 & $1.704^{*}$ & $1.640^{*}$ & $\# 3$ and \#15 & $0.92^{*}$ & 0.28 \\
\hline \multirow[t]{4}{*}{$0^{\pi}$} & JAN/2009 & 5.164 & $15.236^{*}$ & 59 & 61 & 1.629 & 1.593 & $\# 9$ and \#18 & 0.43 & 0.25 \\
\hline & JAN/2012 & 2.329 & 3.462 & 63 & 56 & $1.594^{*}$ & $1.477^{*}$ & $\# 1$ and \#13 & $0.91^{*}$ & 0.27 \\
\hline & JUL/2012 & 2.379 & $6.018^{*}$ & 69 & 72 & $1.752^{*}$ & $1.711^{*}$ & $\# 1$ and \#2 & 0.75 & 0.31 \\
\hline & JAN/2013 & 10.579 & $7.935^{*}$ & 88 & 96 & $1.673^{*}$ & $1.629^{*}$ & $\# 2$ and \#13 & 0.70 & 0.22 \\
\hline
\end{tabular}

$\left({ }^{*} p<0.01\right)$.

group (Table 3). In terms of allometry, the contribution of size to the shape variation was statistically significant ( $\mathrm{p}<0.01$; both sexes), except in January 2012. The proportion of variance in shape explained by size ranged from $3.46-15.24 \%$, so allometry was removed from the shape analyses. Within each sex, all pairwise size comparisons indicated differences between lowland and hilltop, although some differences were not significant (Table 3). The hilltop mosquitoes were larger than the lowland insects in all populations sampled (Figure 6). The $\mathrm{Q}_{\mathrm{ST}}$ values for shape were similar in all comparisons and $\mathrm{Q}_{\mathrm{ST}}$ values for size were considered high only in females sampled in July 2012, January 2013, and in males sampled in January 2012.

\section{CO-I mitochondrial DNA}

All CO-I gene sequences were AT-rich (combined frequency of $71.23 \%$ ), which is expected within the Insecta $[45,46]$. There were no non-functional genes (i.e., pseudogenes) as shown by the clear electropherograms, absence of stop codons, and prevalence of synonymous substitutions. A total of 38 substitutions occurred in the mtDNA sequences: 34 were synonymous transitions and four were non-synonymous transversions (Ser $>$ Asn, Leu $>$ Met, Phe $>$ Leu, Met $>$ Leu). The main genetic findings are described in Table 4.

Haplotypic diversity was high, and the $\Phi$ st of 0.085 indicates moderate genetic differentiation between the lowland and hilltop populations. The values of Tajima and $\mathrm{Fu} \& \mathrm{Li}$ were not considered significant, accepting the hypothesis of strict neutrality. In spite of this, the graph of mismatch distribution (Figure 7) shows that the populations will probably not have constant size, but are population in growth-decline $(\mathrm{p}<0.001)$.

Among the 96 sampled specimens, we found 60 different haplotypes, only two of which were shared between lowland and hilltop mosquitos (haplotypes \#11 and \#40). All the exclusive haplotypes were present in very low frequencies; in most cases, only one individual harboured the haplotype. The calculated Jaccard index was $0.033(\mathrm{p}<0.05)$, showing low similarity between the two microenvironments. The minimum spanning network
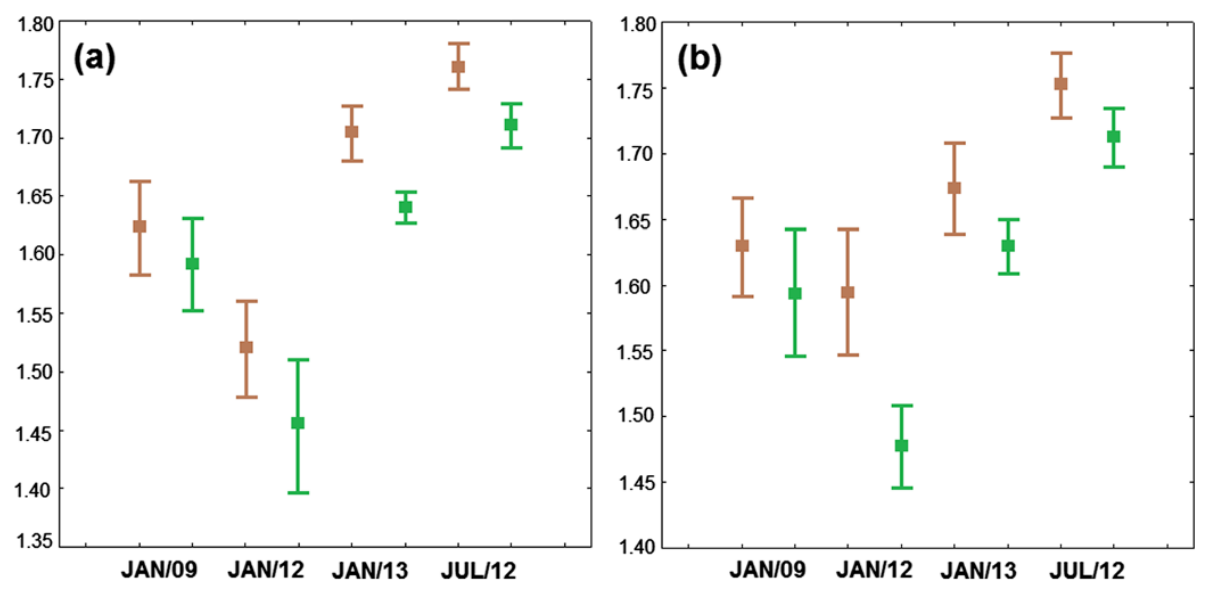

Figure 6 Centroid size. Descriptive statistics of wing sizes (in $\mathrm{mm}$ ) from all populations of sampled Anopheles cruzii of lowland (green) and hilltop (brown). (a) Females; (b) Males. 
Table 4 Summary statistics for genetic data of Anopheles cruzii: haplotypes, nucleotide diversity and neutrality's tests

\begin{tabular}{lllllll}
\hline Microenvironment & $\mathbf{H} / \mathbf{n}$ & Polymorphic sites & $\mathbf{h}$ & $\boldsymbol{\pi}$ & $\mathbf{D}_{\mathbf{T}}$ & \multicolumn{1}{c}{} \\
\hline Hilltop & $33 / 55$ & $25 / 407$ & 0.976 & 0.0087 & -1.299 & -1.702 \\
Lowland & $29 / 41$ & $28 / 407$ & 0.980 & 0.0124 & -0.867 & -1.363 \\
Hilltop + Lowland & $60 / 96$ & $38 / 407$ & 0.986 & 0.0107 & -1.424 & -2.156 \\
\hline
\end{tabular}

$\mathrm{H}=$ number of haplotypes; $\mathrm{n}=$ individuals sampled; $\mathrm{h}=$ haplotype diversity; $\pi=$ nucleotide diversity; $\mathrm{D}_{\mathrm{T}}=$ Tajima's $\mathrm{D}$ test; $F=F u$ and Li's $\mathrm{F}$ test.

illustrates the mutational relationship of the An. cruzii haplotypes (Figure 8).

\section{Discussion}

The An. cruzii hilltop and lowland populations showed a pattern of wing divergence between all sampled sets. The minimum ground distance between these micro-regions is approximately $470 \mathrm{~m}$, so the mosquitoes could fly between them [47]. Apparently, there are other ecological reasons that prevent them from freely circulating between altitudes. The preference for specific biotopes and bromeliads within each microenvironment may differ in each population. The micro-environmental context may influence behavior, genetic drift, natural selection and indirectly drive genotype and phenotype. This hypothesis was also discussed in a study case conducted in the same locality: Marques et al. [19] found that the volume of water in lowland bromeliads is significantly higher than in hilltop plants; this could be a determining factor in the preferences of each population. The landscapes of hilltop and lowland also differ in other respects: the levels of sunlight, vegetation cover, relative humidity, and resident plant species may influence the preference of anopheline populations and, thus, their differentiation.

Veloso [48] observed that the species is indifferent to special microclimates, being found in large quantity in various types of biotopes. If the individuals were under selective pressure, as has already been observed in other species of culicids, there would be a tendency to reduce the intraspecific variability of this characteristic [49]; this was not observed in our study. However, the separation of groups by wing shape indicates a divergence within the species An. cruzii. Micro-environmental variation might affect wing shape, and this interference can be related to flight performance in Culicidae [50]. In Drosophila, numerous genes control natural variation in wing shape [51], and the development of shape requires a cascade of genes that act throughout development; this may explain why changes in wing shape are sensitive to a variety of environmental stressors [52] and that minor perturbations during development can lead to large changes in shape [53].

Although wing shape varied over time, altitudinal structure and sexual wing dimorphism were maintained. Despite its dynamic and rich variability, wings are evolutionarily informative and appear to be canalized. The morphological variation differential for each sex can be the result of different selective pressures that can shape the wings as part of their adaptations. Models by Lande [54] and Lande and Arnold [55] assume that the genetic basis for sexual dimorphism is polygenic. Males and females have different ecological roles in the environment and use their wings differently; this could motivate sex-specific natural selection [56]. The comparison of wing shape consensus after Procrustes superimposition revealed that the most influential landmark in the majority of populations was landmark \#9, localized in the wing border. It seems that this anatomical mark is important in sexual dimorphism of this species. According to Dujardin [30], the landmarks are differentially affected by the same displacement. The posterior border of the

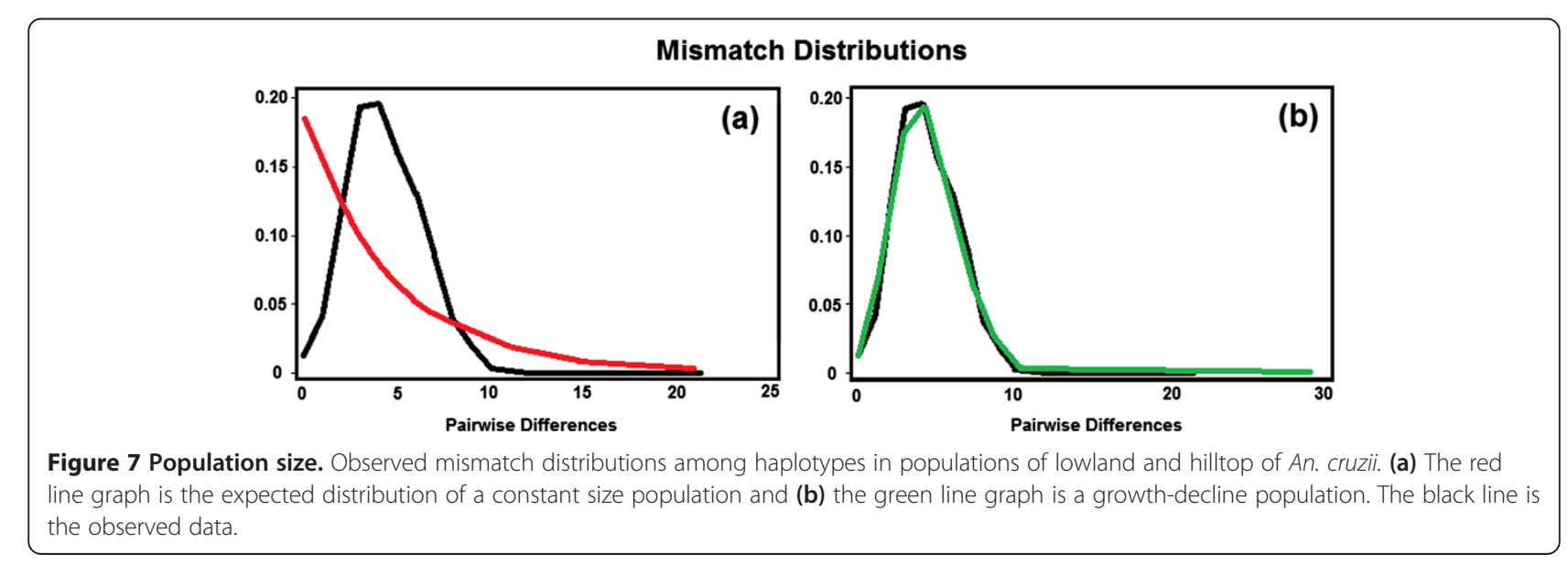




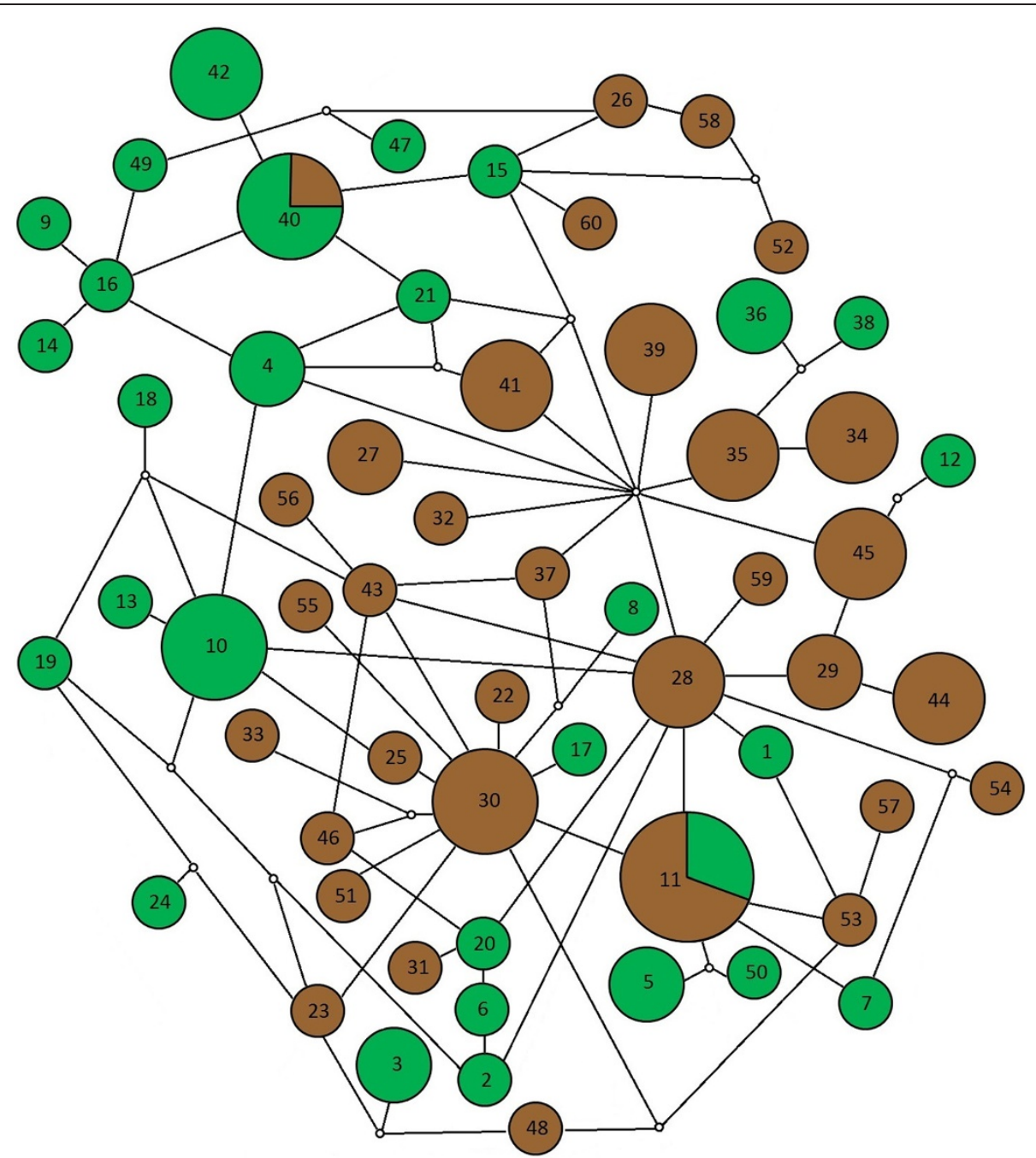

Figure 8 Parsimony network of the $\mathbf{6 0}$ haplotypes. Circle sizes correspond to the haplotype frequency in lowland (green) and hilltop (brown). The white circles represent a single mutational event. The smallest circles correspond to only one individual.

wing moved in opposite ways, depending on the external stimulus [30]. In terms of allometry, the contribution of size to the shape variation was statistically significant for most populations; however, the elimination of allometry before CVA allowed us to say that the observed variation probably is not due to plasticity.

In this study, we found a very high number of haplotypes for each microenvironment sampled, only two of which were shared between lowland and hilltop insects. The nucleotide diversity was also high, indicating that the analysed fragment of CO-I is extremely polymorphic in An. cruzii. The large number of haplotypes found differs from other studies of the anopheline CO-I gene $[57,58]$. The high frequency of transitions in the third codon position indicates that the analysed groups diverged recently [59]. There have been no published population-based studies of mtDNA in An. cruzii [60]. The large quantity of haplotypes found in micro-environmental comparisons may reflect the proximity to the centre of origin of this species. The distribution of An. cruzii is restricted to South America [3]; thus, its centre of origin is also located in this region. In general, older populations have a higher diversity than younger populations [61,62].

Comparing the values of genetic diversity $\left(\Phi_{\mathrm{ST}}\right)$ with those of morphological diversity (Qst), we noted that Qst of shape and size, were higher. This reveals a greater degree of evolution in the wing than in the CO-I gene; therefore, these markers evolve at different rates. If the markers were neutral they should converge to the same value [30], which is not the case here. In An. cruzii, the CO-I gene was so polymorphic that might not be the most appropriate marker to demonstrate a clear pattern of divergence between populations, as in Anopheles darlingi [63,64] or Aedes aegypti [65]. Although Tajima [39] and Fu and Li's [40] F neutrality tests did not observe significant negative population values (Table 4), 
the results of mismatch distribution analyses indicated that the population probably did not have a constant size, but remained in growth-decline (Figure 7).

Studies of Culex [66] and Aedes [67] have demonstrated that altitudinal stratification can be revealed by individual wing morphology; however those studies have compared distant populations, with altitudes ranging from 800 to $2130 \mathrm{~m}$. Our study revealed variation between closely located populations, where the geographical distance between microenvironments was not substantial (see Additional file 1). An incidental hypothesis of our work is that the lowland/hilltop populations are undergoing an incipient speciation process. The presence of cryptic species under the nominal species An. cruzii has been reported in other localities, but the occurrence of this phenomenon in Cananéia is still controversial $[68,69]$. To test this hypothesis, new studies should be performed using the other taxonomical markers traditionally employed to diagnose cryptic species in An. cruzii: chromosomes [68,70,71].

\section{Conclusions}

The data for wing shape and gene CO-I were concordant, which probably indicates the vertical structure of An. cruzii in the Cananéia region. Despite microevolution over time, the altitudinal structure and sexual wing dimorphism were maintained in this species. The hilltop and lowland populations differ in several aspects, which might be also reflected in their vectorial capacity. Our proposed scenario relies on theoretical conditions conducive to development of parapatric speciation, in which there is no specific extrinsic barrier to gene flow. The population is continuous, but the individuals do not cross randomly [72]. They are more prone to cross with their geographical neighbours than with individuals of a different group. There is continuity between the landscape microenvironments, because the bromeliaceous breeding sites are present throughout the forest and there are no physical barriers between lowland and hilltop. However, the morphological and molecular evidence suggests that the anophelines do not pass randomly through the vertical stratum. Knowledge of these phenomena will support our understanding of the transmission dynamics of the Plasmodium sp. It is also possible that the gene flow patterns differ throughout the year or that population makes demographic substitution. The gene variability in populations is unknown; however, if this scenario changes, it can be used to understand the epidemiology of malaria in the region. It opens a demand for studies on sexual dimorphism and genetic basis of altitudinal preference.

\section{Additional file}

Additional file 1: Map and geographic coordinates of collection sites.

\section{Competing interests}

The authors declare that they have no competing interests.

\section{Authors' contributions}

CL, MAMS and LS conceived the study, carried out data analysis, results interpretation and written the manuscript. $\mathrm{CL}$ and TCM collected data in the field. All authors approved the final version of the manuscript.

\section{Acknowledgements}

A number of people provided field and laboratory assistance or mosquito samples used in the study. We are especially grateful to Luiz Carlos de Oliveira, Décio Wach, Jair Donizete da Silva, Francisco Alves dos Santos, Rui de Lima and Solange Schiessl Lorenz. Financial support: CNPq no. 140964/2013-4; CAPES Research Grant \#23038.005274/2011-24; FAPESP no. 2011/30397-7; FAPESP no. 2013/05521-9.

\section{Author details}

${ }^{1}$ Instituto Butantan, Avenida Vital Brazil, 1500, São Paulo CEP 05509-300, Brazil. 'Biologia da Relação Patógeno-Hospedeiro, Instituto de Ciências Biomédicas, University of Sao Paulo, Av. Prof. Lineu Prestes, 2415, São Paulo CEP 05508-000, Brazil. '3Departamento de Epidemiologia, Faculdade de Saúde Pública, Universidade de São Paulo, 1500, São Paulo CEP 05509-300, Brazil. ${ }^{4}$ Instituto de Medicina Tropical, Avenida Dr. Enéas Carvalho de Aguiar 470, São Paulo CEP 05403-000, Brazil.

Received: 26 June 2014 Accepted: 29 November 2014

Published online: 16 December 2014

\section{References}

1. Consoli RAGB, Lourenço-de-Oliveira R: Principais mosquitos de importância sanitária no Brasil. Rio de Janeiro: Fiocruz Press; 1994.

2. Branquinho MS, Marrelli MT, Curado I, Natal D, Barata JMS, Tubaki R, Carréri-Bruno GC, Menezes RT, Kloetzel JK: Infecção do Anopheles (Kerteszia) cruzii por Plasmodium vivax e Plasmodium vivax variante VK247 nos Municípios de São Vicente e Juquitiba, São Paulo. Rev Panam Salud Publica 1997, 2:122-134.

3. Forattini OP: Culicidologia médica. São Paulo: EDUSP Press; 2002.

4. Forattini OP, Gomes AC, Natal D, Santos JLF: Observações sobre a atividade de mosquitos Culicidae em matas primitivas da planície e perfis epidemiológicos de vários ambientes do Vale do Ribeira, São Paulo, Brasil. Rev Saude Publ 1986, 20:178-203.

5. Forattini OP, Kakitani I, Massad E, Marucci D: Studies on mosquitoes (Diptera: Culicidae) and anthropic environment: biting activity and blood-seeking parity of Anopheles (Kerteszia) in South-Eastern Brazil. Rev Saude Pub/ 1996, 30:107-114.

6. Forattini OP, Gomes ADC, Natal D, Kakitani I, Marucci D: Freqüência domiciliar e endofilia de mosquitos Culicidae no Vale do Ribeira, São Paulo, Brasil. Rev Saude Publ 1987, 21:188-192.

7. Gadelha P: From "forest malaria" to "bromeliad malaria": a case-study of scientific controversy and malaria control. Parassitologia 1994, 36:175-195.

8. Tubaki RM, Carreri-Bruno GC, Glasser CM, Ciaravolo RMC: Biting activity of Anopheles (Kerteszia) cruzii (Diptera, Culicidae) in domiciliary habitats in the Southern Atlantic Forest, Peruibe, State of São Paulo, Brazil. Rev Bras Entomol 1993, 37:569-575.

9. Azevedo AL: Aspectos da epidemiologia da malária e da biologia de Anopheles (Kerteszia) cruzii Dyar \& Knab em vales montanhosos do sistema de Mata Atlântica. Rio de Janeiro: Instituto Oswaldo Cruz Press; 1997.

10. Carvalho MED, Glasser CM, Ciaravolo RM, Etzel A, Dos Santos LA, Ferreira CS: Sorologia de malária vivax no foco Aldeia dos Índios, município de Peruíbe, Estado de São Paulo, 1984 a 1986. Cadernos de Saúde Pública 1988, 4:276-292

11. Curado I, Duarte AMR, Lal AA, Oliveira SG, Kloetzel JK: Antibodies anti-bloodstream and circumsporozoite antigens (Plasmodium vivax and Plasmodium malariae/P. brasilianum) in areas of very low malaria endemicity in Brazil. Mem Inst Oswaldo Cruz 1997, 92:235-243.

12. Amaral J: Infecção natural do Nyssorhynchus (Kerteszia) cruzii e bellator (Diptera Culicidae). Folha med 1942, 15:1-9.

13. Coutinho JO, Rachou RG, Ricciardi I: Contribuição para o conhecimento dos transmissores de malária no Brasil - Anopheles (K) cruzii e bellator. Arq Hig 1943, 13:115-127. 
14. Duarte AMR, Pereira DM, de Paula MB, Fernandes A, Urbinatti PR, Ribeiro AF, Malafronte RS: Natural infection in anopheline species and its implications for autochthonous malaria in the Atlantic forest in Brazil. Parasit Vectors 2013, 6:58.

15. Rachou RG, Ferreira MO: Kerteszia as the group most responsible for malaria in the State of Santa Catarina. Rev Bras Malar Doen Trop 1966, 18:691.

16. Deane LM, Ferreira Neto JA, Deane MP, Silveira IP: Anopheles (Kerteszia) cruzii, a natural vector of the monkey malaria parasites, Plasmodium simium and Plasmodium brasilianum. Trans Roy Soc Trop Med Hyg 1970, 4:64.

17. Deane LM: Simian malaria in Brazil. Mem Inst Oswaldo Cruz 1992 $87: 1-20$.

18. Deane LM, Ferreira-Neto JA, MOURA LM: The vertical dispersion of Anopheles (Kerteszia) cruzii in a forest in Southern Brazil suggests that human cases of malaria of simian origin might be expected. Mem Inst Oswaldo Cruz 1984, 79:461-463.

19. Marques TC, Bourke BP, Laporta GZ, Sallum MAM: Mosquito (Diptera: Culicidae) assemblages associated with Nidularium and Vriesia bromeliads in Serra do mar, Atlantic Forest. Brazil Parasit Vectors 2012, 5:41.

20. Prefeitura Municipal da Estância de Cananéia. São Paulo. Brazil [http://www.cananeia.sp.gov.br/index.php?exibir=secoes\&ID=50]

21. Centro de Pesquisas Meteorológicas e Climáticas aplicadas à Agricultura (CEPAGRI). Meteorologia Universidade Estadual de Campinas - UNICAMP; [http://www.cepagri.unicamp.br/]

22. IBGE (Instituto Brasileiro de Geografia e Estatística). [http://www.ibge.gov. $\mathrm{br} / \mathrm{home} /]$

23. Belkin JN, Schick RX, Heinemann SJ: Mosquito studies (Diptera: Culicidae). VI. Mosquitoes originally described from North America. Contrib Am Entomol Inst 1966, 1:1-39.

24. Sallum MAM, Dos Santos CL, Wilkerson RC: Studies on Anopheles (Kerteszia) homunculus Komp (Diptera: Culicidae). Walter Reed Army Inst of Res Silver Spring MD Dept Entomol 2009, 3:40.

25. Lorenz C, Marques TC, Sallum MAM, Suesdek L: Morphometrical diagnosis of the malaria vectors Anopheles cruzii, An. homunculus and An. bellator. Parasit Vectors 2012, 5:1-7.

26. Vidal PO, Rocha LS, Peruzin MCJ: Wing diagnostic characters for mosquitões Culex quinquefasciatus and Culex nigripalpus (Diptera; Culicidae). Rev Bras Entomol 2011, 55:132-142.

27. Rohlf FJ: TpsDig, digitize landmarks and outlines [Computer program]. Version 2.05. Dept Ecol.\& Evol., St. Univ. New York: Stony Brook; 2005.

28. Rohlf FJ: TpsRelw, relative warps analysis [Computer program]. Version 1.36 Dept Ecol.\& Evol., St. Univ. New York: Stony Brook; 2003.

29. StatSoft, Inc: Statistica for Windows [Computer program manual]. Tulsa: OK: StatSoft, Inc; 2004. Available at: [http://www.statsoft.com]

30. Dujardin JP: Morphometrics applied to medical entomology. Infect Genet Evol 2008, 8:875-890

31. Spitze K: Population structure in Daphnia obtusa: quantitative genetic and allozymic variation. Genetics 1993, 135:367-374

32. Dujardin JP: COO, MOG and COV for Windows [Computer program manual]. Marseille: Institut de Recherches pour le Développement; 2010.

33. MOME (Morphometrics in Medical Entomology). [http://mome-clic.com/]

34. Klingenberg CP: MorphoJ: an integrated software package for geometric morphometrics. Mol Ecol Res 2011, 11:353-357.

35. TPS (Morphometrics at SUNY Stony Brook). [http://life.bio.sunysb.edu/ morph/]

36. Jowett T: Preparation of Nucleic Acids. In Drosophila, a Practical Approach Press: Oxford, U.K; 1986.

37. Zhang DX, Hewitt E: Assessment of the universality and utility of a set of conserved mitochondrial COI primers in insects. Insect Mol Biol 1996, 6:143-150.

38. Tamura K, Dudley J, Nei M, Kumar S: MEGA 5.0: Molecular Evolutionary Genetics Analysis (MEGA) software version 5.0. Mol Biol Evol 2007, 24:1596-1599.

39. Tajima F: Statistical method for testing the neutral mutation hypothesis by DNA polymorphism. Genetics 1989, 123:585-595.

40. Fu YX, Li WH: Statistical tests of neutrality of mutations. Genetics 1993, 133:693-709.

41. Rozas J, Sánchez-DelBarrio JC, Messeguer X, Rozas R: DnaSP, DNA polymorphisms analyses by the coalescente and other methods. Bioinformatics Application Note 2003, 19:2496-2497.
42. Excoffier L, Laval G, Schneider S: Arlequin ver. 3.0: an integrated software package for population genetics data analysis. Evol Bioinformatics Online 2005, 1:47-50.

43. Clement M, Posada DCKA, Crandall KA: TCS: a computer program to estimate gene genealogies. Mol Ecol 2000, 9:1657-1659.

44. Real R: Tables of significant values of Jaccard's index of similarity. Miscellània Zoològica 1999, 22:29-40.

45. Bernasconi MV, Valsangiacomo C, Piffaretti JC, Ward PI: Phylogenetic relationships among Muscoidea (Diptera: Calyptratae) based on mitochondrial DNA sequences. Insect Mol Biol 2000, 9:67-74.

46. Mirabello L, Conn JE: Molecular population genetics of the malaria vector Anopheles darlingi in Central and South America. Heredity 2006, 96:311-321.

47. Ferreira E, Castro-Filho J, Tomich A, Sá FT: Estudo sobre o raio de vôo do Anopheles (Kerteszia) cruzii e do Anopheles (Kerteszia) bellator em Guaratuba, litoral do Estado do Paraná. Brasil Rev Bras Malariol Doen Trop 1969, 21:819-822.

48. Veloso HP, Moura JV, Klein RM: Delimitação Ecológica dos anofelinos do subgênero Kerteszia na região costeira do sul do Brasil. Mem Inst Oswaldo Cruz 1956, 54:517-520.

49. Dujardin JP, Costa J, Bustamante D, Jaramillo N, Catalá S: Deciphering morphology in Triatominae: the evolutionary signals. Acta Trop 2009, 110:101-111.

50. Hoffmann AA, Shirriffs J: Geographic variation for wing shape in Drosophila serrata. Evolution 2002, 56:1068-1073.

51. Weber K, Eisman R, Morey L, Patty A, Sparks J, Tausek M, Zeng ZB: An analysis of polygenes affecting wing shape on chromosome 3 in Drosophila melanogaster. Genetics 1999, 153:773-786.

52. Garcia-Bellido A, De Celis JF: Developmental genetics of the venation pattern of Drosophila. Annu Rev Genet 1992, 26:275-302.

53. Emlen DJ, Nijhout HF: The development and evolution of exaggerated morphologies in insects. Annu Rev Entomol 2000, 45:661-708.

54. Lande R: Sexual dimorphism, sexual selection, and adaptation in polygenic characters. Evolution 1980, 4:292-305.

55. Lande R, Arnold SJ: Evolution of mating preference and sexual dimorphism. J Theor Biol 1985, 117:651-664.

56. Wekesa JW, Brogdon WG, Hawley WA, Besansky NJ: Flight tone of field collected populations of Anopheles gambie and An. arabiensis (Diptera: Culicidae). Physiol Entomol 1998, 23:289-294.

57. Oshagui MA, Shemshad KH, Yaghobi-Ershadi MR, Pedram M, Vatandoost $H_{\text {, }}$ Abaie MR, Akbarzadeh K, Mohtarami F: Genetic structure of the malaria vector Anopheles superpictus in Iran using mitochondrial cytochrome oxidase (COI and COII) and morphologic markers: a new species complex? Acta Trop 2006, 101:241-248.

58. Patsoula E, Samanidou-Voyadjoglou A, Spanakos G, Kremastinou J, Nasioulas G, Vakalis C: Molecular characterization of the Anopheles maculipennis complex during surveillance for the, Olympic Games in Athens. Med Vet Entomol 2004, 2007(21):36-43.

59. Simon C, Frati F, Beckenbach A, Crespi B, Liu H, Flook P: Evolution, weighting, and phylogenetic utility of mitochondrial gene sequences and a compilation of conserved polymerase chain reaction primers. Ann Entomol Soc Am 1994, 87:651-701.

60. Loaiza JR, Bermingham E, Sanjur OI, Scott ME, Bickersmith SA, Conn JE: Review of genetic diversity in malaria vectors (Culicidae: Anophelinae). Infec Gen Evol 2012, 12:1-12.

61. Molina-Cruz A, De Merida AMP, Mills K, Rodriguez F, Schoua C, Yurrita MM, Black WC: Gene flow among Anopheles albimanus populations in Central America, South America, and the Caribbean assessed by microsatellites and mitochondrial DNA. Am J Trop Med Hyg 2004, 71:350-359.

62. Kambhampati S, Rai KS: Mitochondrial DNA variation within and among populations of the mosquito Aedes albopictus. Genome 1991, 34:288-292.

63. Motoki MT, Suesdek L, Bergo ES, Sallum MAM: Wing geometry of Anopheles darlingi Root (Diptera: Culicidae) in five major Brazilian ecoregions. Infect Gen Evol 2012, 12:1246-1252.

64. Moutinho PR, Gil LH, Cruz RB, Ribolla PE: Population dynamics, structure and behavior of Anopheles darlingi in a rural settlement in the Amazon rainforest of Acre, Brazil. Malaria J 2011, 10:174.

65. Scarpassa VM, Cardoza TB, Cardoso RP: Population genetics and phylogeography of Aedes aegypti (Diptera: Culicidae) from Brazil. Am J Trop Med Hyg 2008, 78:895-903.

66. Demirci B, Lee Y, Lanzaro GC, Alten B: Altitudinal genetic and morphometric variation among populations of Culex theileri Theobald 
(Diptera: Culicidae) from Northeastern Turkey. J Vector Ecol 2011, 37:197-209.

67. Kuclu O, Aldemir A, Demirci B: Altitudinal variation in the morphometric characteristics of Aedes vexans Meigen from northeastern Turkey. J Vector Ecol 2011, 36:30-41.

68. Carvalho-Pinto CJD, Lourenço-de-Oliveira R: Isoenzimatic analysis of four Anopheles (Kerteszia) cruzii (Diptera: Culicidae) populations of Brazil. Mem Inst Oswaldo Cruz 2004, 99:471-475.

69. Malafronte RS, Marrelli MT, Ramirez CCL, Nassar MN, Marinotti O: Intraspecific variation of second internal transcribed spacer of nuclear ribosomal DNA among populations of Anopheles (Kerteszia) cruzii (Diptera: Culicidae). J Med Entomol 2007, 44:538-542.

70. Ramirez CCL, Dessen EMB: Cytogenetic analysis of a natural population of Anopheles cruzii. Rev Bras Gen 1994, 17:41-46.

71. Ramírez CCL, Dessen EMB: Chromosomal evidence for sibling species of the malaria vector Anopheles cruzii. Genome 2000, 43:143-151.

72. Templeton AR: Genética de populações e teoria microevolutiva. São Paulo: Holos Press; 2011.

doi:10.1186/s13071-014-0581-8

Cite this article as: Lorenz et al.: Altitudinal population structure and microevolution of the malaria vector Anopheles cruzii (Diptera: Culicidae). Parasites \& Vectors 2014 7:581.

\section{Submit your next manuscript to BioMed Central and take full advantage of:}

- Convenient online submission

- Thorough peer review

- No space constraints or color figure charges

- Immediate publication on acceptance

- Inclusion in PubMed, CAS, Scopus and Google Scholar

- Research which is freely available for redistribution 